\title{
Tecnologia Assistiva, Impressão 3D e Indústria 4.0
}

\author{
Assistive Technology, 3D Printing and Industry 4.0
}

SOARES, Juliana Maria Moreira, Doutoranda em Design, Universidade de São Paulo

julianammsoares@usp.br

FONSECA DE CAMPOS, Paulo Eduardo, Livre-docente, Universidade de São Paulo

pfonseca@usp.br

\section{Resumo}

Este artigo tem como intenção traçar correlações preliminares no campo de desenvolvimento de produtos envolvendo Tecnologias Assistivas, impressão 3D e a Indústria 4.0. A pesquisa apresenta análises sobre o cenário potencial de aplicação das premissas da chamada Indústria 4.0, um assunto relativamente recente no Brasil, na área de produtos focados na pessoa com deficiência, uma indústria que ainda se mostra atualmente incipiente e com pouco poder de atendimento ao seu público no país. Como considerações finais, os autores trazem reflexões e proposições possíveis de cenários produtivos de conjugação destes três campos.

Palavras Chave: tecnologia assistiva; impressão 3d; indústria 4.0; desenvolvimento de produtos.

\begin{abstract}
This article intends to make preliminary correlations in the field of product development involving Assistive Technologies, 3D printing and Industry 4.0. The research presents analyzes about the potential scenario of application of the premises of the so-called Industry 4.0, a relatively recent subject in Brazil, in the area of products focused on people with disabilities, an industry that is still currently incipient and with little potential to offer possibilities for its national public. As final considerations, the authors bring reflections and possible propositions of productive scenarios of conjugation of these three fields.
\end{abstract}

Keywords: assistive technology; 3D printing; industry 4.0; product development. 


\section{Introdução}

A Tecnologia Assistiva (TA) é um termo ainda pouco comum na atualidade, mesmo que seus primórdios estejam localizados na época da Segunda Guerra Mundial, quando um grande contingente de combatentes retornava aos Estados Unidos com alguma deficiência, demandando iniciativas e pesquisas na área de reabilitação (ROBITAILLE, 2010). No Brasil, o termo tem sua tradução oficial no ano de 1988 (BERSCH, 2013), e apenas mais recentemente pesquisas e estudos no campo vêm ganhando destaque. A área, apesar de essencial ao desenvolvimento de uma sociedade inclusiva, ainda não é suficientemente evoluída no país - mas, no entanto, novas iniciativas vêm se destacando como interessantes aliadas em determinados percursos do campo.

Nesta linha, é possível falar da fabricação digital, especificamente da impressão tridimensional, como um aporte ao desenvolvimento nesta área de TA. Nota-se que pequenos desenvolvedores, laboratórios e empresas, como startups, já têm se utilizado destas ferramentas com relativa frequência, visando a construção de seus próprios percursos produtivos.

O contexto de emergência desses maquinários, muito frequentemente, encontra-se vinculado ao da chamada Indústria 4.0 - outro termo também desconhecido para grande parte das pessoas. A sobreposição de tecnologias e de mundos, físicos, virtuais e biológicos, é uma das premissas para a existência desta indústria, cada vez mais autônoma e dotada de um tipo particular de inteligência, que traz consigo grandes promessas de inovação e personalização de sua produção. Em uma contemporaneidade cada vez mais transdisciplinar e transversal em sua base de conhecimentos, este cenário chama a atenção para a potencialidade de aplicação de suas técnicas para o fomento do campo das Tecnologias Assistivas, justificando o estímulo a esse tipo de pesquisa atualmente.

Desta maneira, o artigo busca realizar uma exploração preliminar, abordando uma problemática que conecta estes campos a possibilidades aplicáveis na área das Tecnologias Assistivas, tendo em vista um alcance nacional. Objetiva-se a geração de reflexões e considerações acerca desse panorama, com base em estudos bibliográficos e vivências dos autores na área, para serem trazidos como resultados da presente abordagem teórica.

\section{Metodologia}

Como fundamentação metodológica para este estudo, foram utilizadas distintas técnicas para a coleta dos dados necessários, tendo sentido essa abordagem ao se pensar em um estudo de 
natureza qualitativa (CRESWELL, 2010). Métodos como o de pesquisa bibliográfica em fontes primárias e secundárias, ao lado de um forte aporte situado sobre observações participantes e não-participantes, frutos da vivência dos pesquisadores dentro do campo de pesquisa (como em múltiplos laboratórios de fabricação digital, núcleos de desenvolvimento de TA e cenários de utilização de Tecnologias Assistivas, como em instituições de reabilitação), foram algumas das técnicas empregadas neste panorama. $\mathrm{O}$ artigo ainda se situa sobre um eixo de exploração e de descrição, fundamental para a compreensão de fenômenos emergentes, tais quais os aqui colocados. A presente pesquisa se encontra aprovada pelo Comitê de Ética e Pesquisa (Plataforma Brasil) $)^{1}$.

\section{Cenários da deficiência e as Tecnologias Assistivas}

Um dado expressivo e sempre presente quando o assunto tratado é a pessoa com deficiência (PcD) e as questões voltadas a essa porção populacional, é a quantidade da indivíduos que se encaixa neste quadro, totalizando 45,6 milhões no país - cerca de $24 \%$ da população brasileira ${ }^{2}$, chegando a $10 \%$ em um contexto global ${ }^{3}$. Neste número estão presentes pessoas com os mais diversos graus e tipos de deficiência, sendo a visual e a motora as deficiências mais expressivas em porcentual de ocorrência.

Enquanto parte das PCD's irão desempenhar suas atividades rotineiras sem maiores entraves, para outras parcelas desse segmento social a vida cotidiana só será possível por meio da chamada Tecnologia Assistiva (TA). Dentre as TA são encontrados produtos e serviços que potencializam as capacidades e a performance da PcD, que convive com alguma diminuição funcional proporcionada por sua deficiência. A definição de Galvão Filho e Damasceno (2008, p. 05) resume o conceito: "a Tecnologia Assistiva é toda ferramenta, recurso ou processo com a finalidade de proporcionar uma maior independência e autonomia para a pessoa com deficiência". Como exemplos, é possível citar aparatos como cadeiras de rodas e softwares de leitura de telas de computadores, os quais visam, respectivamente, a emancipação de pessoas com deficiência física e visual na realização de suas atividades.

\footnotetext{
1 A Plataforma Brasil é um sistema online de cadastro para a avaliação de pesquisas envolvendo seres humanos, de acordo com os Comitês de Ética elencados. Disponível em: < http://plataformabrasil.saude.gov.br/login.jsf > Acesso dia 20 fev. 2018.

2 Dados levantados segundo censo do IBGE, realizado em 2010.

3 No mundo, a Organização Mundial da Saúde (OMS) indica que aproximadamente 650 milhões de pessoas convivem com alguma deficiência, conforme publicado no Relatório Mundial sobre a Deficiência, em 2012.
} 
O cenário de envelhecimento populacional não é mais uma situação exclusiva dos chamados países desenvolvidos, os quais já contam com um incremento nas taxas de expectativa de vida há décadas. Tal envelhecimento consiste em um processo próprio das sociedades modernas (VERAS, 2009), e desta forma, esse panorama vem se concretizando em países dos mais distintos continentes, não fugindo à situação o Brasil, que vem experimentando um crescente movimento de inversão da pirâmide etária. Envelhecer, de maneira alguma, equivale a um imperativo de se adquirir uma deficiência - e cada vez mais se prova o contrário, com evidências que mostram que a vida na terceira idade tem ocorrido, frequentemente, em progressiva atividade e autonomamente. No entanto, este é um fenômeno que deve ser destacado dentro do crescimento das ocorrências de deficiência, dado que tal deficiência existente entre a parcela idosa não expõe nada mais que um reflexo do acúmulo de riscos ocorrido no decorrer da vida, podendo vir a trazer diminuição de capacidades funcionais e/ou doenças crônicas à pessoa (SEGALLA; DA SILVA; PEDROSO, 2008; VERAS, 2009, OMS, 2012).

Quadros menos naturais também se conjugam com a situação de crescimento da população com deficiência. Citando um destes no contexto brasileiro, o país lidera vergonhosas estatísticas na área de violência contra a mulher, as quais vêm crescendo nos últimos anos, onde a violência física é apenas uma delas. Esse tipo de agressão gera complexas consequências, que vão além dos graves traumas psicológicos, causando também deficiências em suas vítimas. Estima a $\mathrm{OMS}^{4}$ que $42 \%$ das mulheres no mundo as quais sofreram tal abuso conservam sequelas físicas ou mentais. Coloca-se aqui, ainda, o crescimento de conflitos armados ${ }^{5}$ como outro fator alarmante e que potencialmente alimenta uma situação de crescimento dos índices de deficiência. Pressões de cunho antidemocrático, xenofobia e disputas político-financeiras estão entre os conhecidos motivos dessa crescente, sendo esses fatos noticiados com frequência pelos meios midiáticos - ou não, como em recentes casos nacionais envolvendo populações ribeirinhas, quilombolas e indígenas.

Lembra-se aqui que a necessidade de um olhar mais atento para a área de TA não se traduz em uma proposta de solução para as situações anteriormente expostas ou um mero tratamento de natureza paliativa. A resolução de tais fatores requer um cenário anterior, o qual se constrói a partir de uma conjunção de atividades programadas na esfera de ação pública, como políticas inclusivas, sociais e de saúde, alinhadas a projetos e campanhas de prevenção e, principalmente,

4 Segundo números da OMS expostos em reportagem do jornal Estadão. Disponível em: <http://www.estadao.com.br/noticias/geral,oms-calcula-que-35-das-mulheres-ja-sofreram-violencia,1045282> Acesso em: 27 fev. 2018.

5 Com características distintas de guerras das décadas passadas, cientistas políticos apontam para este crítico panorama de ascensão de conflitos nos tempos atuais. A reportagem completa é do ano de 2017, e consta no jornal Folha de São Paulo, e está disponível em: <http://www1.folha.uol.com.br/ilustrissima/2017/07/1905028-o-papel-dainternet-nos-conflitos-armados-do-seculo-21.shtml> Acesso em: 27 fev. 2018 
na base da educação. No entanto, uma vez expostos a tais eventos, a exemplo dos supracitados, os indivíduos que adquirem uma deficiência têm direito à continuidade de seu percurso normal de vida, com inclusão e independência, sendo a Tecnologia Assistiva uma aliada nesta caminhada (quando bem orientado o uso destes produtos e serviços, e adequados às necessidades individuais vigentes).

Neste próximo tópico, o artigo buscará contextualizar e relacionar como a ascensão das tecnologias de impressão tridimensional pode colaborar nessa necessária tarefa de visualização da área de TA e disponibilização desses produtos, em conformidade com as especificidades dessas populações.

\section{Do bit ao átomo}

Indo no caminho oposto da desmaterialização, por onde se corre atrás de tantos arquivos digitais e digitalizados, bytes, megas e teras, esta é uma era em que ascendem as chamadas impressoras 3D. Deve-se distinguir a impressão 3D aqui focalizada, do sistema $\mathrm{FDM}^{6}$, ainda que ambos sejam tratados, de forma indistinta, pelo nome de manufatura aditiva. Assim, uma atenção ao fato pode ser dada, sob o ponto de vista de que este termo remete ao nome da técnica produtiva, de processo aditivo ${ }^{7}$, o qual é utilizado também por máquinas que fazem uso de outros tipos de tecnologia, como a estereolitografia ${ }^{8}$ e a sinterização a laser $^{9}$. A impressão 3D faz parte do rol das chamadas tecnologias de fabricação digital, as quais incluem outro tipos de ferramentas modernas capazes de gerar modelos tridimensionais, como as fresadoras CNC e as cortadoras a laser - nem tão modernas assim (Figura 01).

60 processo conhecido como FDM (acrônimo de fused deposition modeling) é um dos mais comumente utilizados para prototipagem e também para produtos finais, focado na impressão de baixo volume. Faz uso de filamentos termoplásticos, como o ABS e o PLA, passando por uma cabeça de impressão aquecida (extrusora), para montar as camadas do produto na máquina (ALMEIDA, 2007).

70 processo aditivo forma os objetos por camada a partir de sua base sobre a cama de impressão (ALMEIDA, 2007).

8 A estereolitografia faz uso de resinas de fotopolímeros, depositadas em camadas sob a cama de impressão, conjuntamente com um feixe de laser visando o seu endurecimento (ALMEIDA, 2007).

9 A sinterização à laser também faz uso de laser para que o material em pó seja fundido e moldado na base de impressão da máquina (ALMEIDA, 2007). 
139 Congresso

Pesquisa \&

Desenvolvimento

em Design

Figura 01 - Revolucionário! Professores da Universidade do Texas em Austin, em 1987.

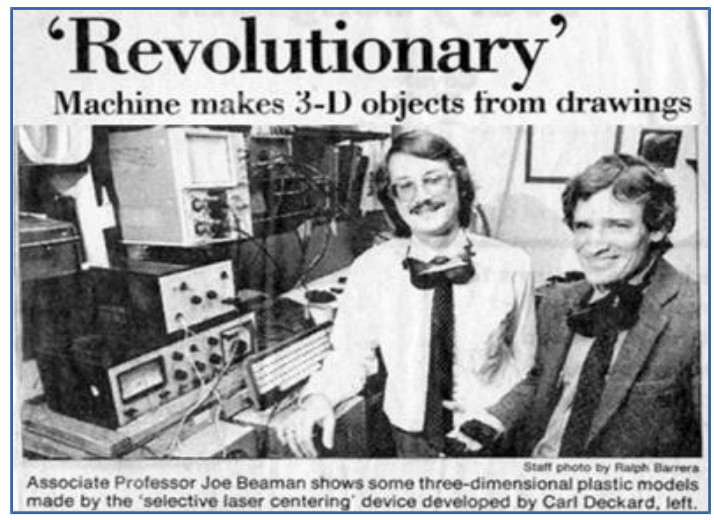

Fonte: LEUNG (2015)

Essas tecnologias 3D têm seu histórico de emergência há mais de 30 anos, quando a primeira máquina de estereolitografia foi patenteada por Charles "Chuck" Hull, em 1986 - que viria a fundar a Stratasys, uma das líderes mundiais na área de impressão 3D (MATIAS; RAO, 2015). Poucos anos depois, universidades norte-americanas estavam em plena ação no desenvolvimento destes tipos de máquinas (Figura 01), e há relatos de que cientistas japoneses e outros norteamericanos já haviam se aventurado na área, mesmo antes da patente de Hull ${ }^{10}$. Entrando no campo das "mães" dessas máquinas, encontram-se as CNC, ou as máquinas de comando numérico computadorizado pioneiras, indo então mais longe ainda na história, há quase 70 anos atrás, aterrissando em um sombrio contexto de invenção durante o período da Guerra Fria (SODERBERG, 2013).

Voltando a tempos mais recentes, pode-se dizer que as impressoras 3D do tipo FDM adquiriram viabilidade comercial apenas nos anos 2000, quando seus valores chegaram a um patamar inferior a mil dólares, proporcionando certa popularização e acessibilidade, principalmente dos modelos desktop (VENTOLA, 2014). Esta tecnologia configura-se como um dos modelos produtivos (ainda que de pequena escala) de maior flexibilidade, proporcionando ao seu usuário a exploração de uma alta complexidade na geometria das peças, aliada a relativos baixos

10 “(...) Hideo Kodama como o primeiro cientista conhecido por ter produzido um sistema de manufatura aditiva funcional sistema de fabricação em 1981. Alan Herbert, da 3M, em 1982 então o seguiu de perto. Desta vez, houve uma prova de que as tecnologias foram desenvolvidas e testadas" (PRINZ et al., 1997 apud MATIAS; RAO, 2015, p. 551, tradução dos autores). 
139 Congresso

Desenvolvimento

em Design

\section{Artigo Completo}

custos e simplicidade, quando comparados a processos como, por exemplo, a usinagem. Características como as citadas são extremamente importantes para a produção de Tecnologias Assistivas, tendo em vista que os altos custos de aquisição destes produtos e a dificuldade de sua personalização e adequação às particularidades individuais são os maiores responsáveis pelo abandono de projetos ou por tornar inacessíveis tais aparatos assistivos (ISHENGOMA; MTAHO, 2014).

Esse diálogo transversal destes campos tem produzido resultados férteis de acordo com o que vem sendo sinalizado, sendo tais casos reportados em múltiplos estudos de periódicos e congressos, que, em sua grande maioria, são estrangeiros. No entanto, no Brasil já se visualizam múltiplos centros de pesquisa, laboratórios e mesmo iniciativas privadas, como startups, engajadas em atividades que ligam a impressão 3D ao campo de TA. Apesar de boa parte desses estudos demonstrar uma visão entusiasta e admirada com a tecnologia, sabe-se que ainda existe considerável progresso a ser feito, e questões relativas à durabilidade dos materiais, acabamentos, tempos de produção, procedimentos metodológicos e financiamento deste tipo de processo são algumas das questões levantadas por pesquisadores nesta via (BUEHLER et al. 2016).

Para finalizar esta seção são apresentadas as figuras 02, as quais explicitam imagens de dois produtos desenvolvidos por meio da impressão 3D. O primeiro deles, à esquerda, criado por uma designer e um engenheiro brasileiros, é um brinquedo educativo e acessível, não somente para crianças com deficiência visual, e atualmente está em fase final de testes junto a usuários. À direita, mostra-se uma prótese de membro superior (mão) impressa pelo projeto Mao3D, da Universidade Federal de São Paulo (UNIFESP), a qual pode ser personalizada de acordo com as necessidades dos indivíduos e, posteriormente, doada aos mesmos.

Figura 02. O Togotoy à esquerda e a prótese, à direita.
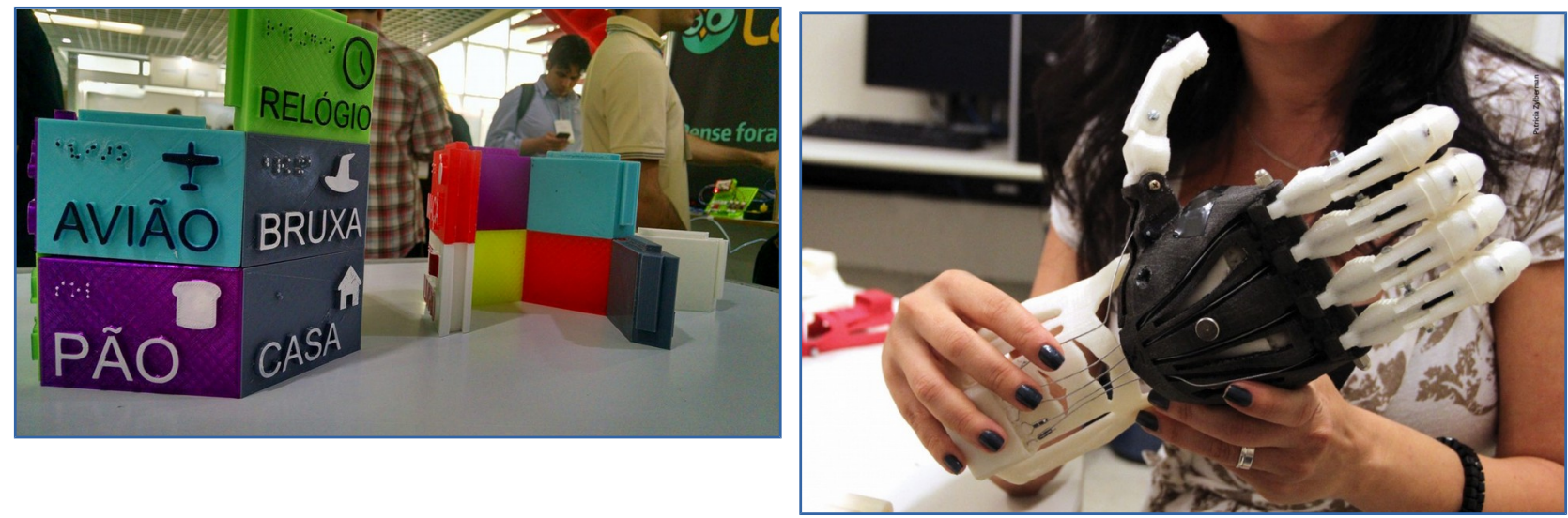

Fontes: FAB LAB LIVRE SP (2016) e UNIFESP (2015). 


\section{A revolução não será atomizada?}

O termo Indústria 4.0 surgiu na Alemanha no ano de 2011, na ocasião da apresentação de uma ação estratégica na área de tecnologia ao governo alemão. Um alto custo de investimento por parte do governo central visaria tornar inteligentes as fábricas do país (AZEVEDO, 2017). Atribuir essa característica humana a um cenário artificial significaria, então, relacionar os processos desses meios de produção a sistemas autônomos e paradigmas diversos, como robóticos e de Internet das Coisas ${ }^{11}$, fundindo tecnologias múltiplas e domínios físicos, digitais e inclusive biológicos, com velocidade e eficiência. Resumidamente, este é o cenário de atividades da chamada indústria 4.0.

Para múltiplos autores e entusiastas da área, esses conjunto de aplicabilidades faz parte da chamada quarta revolução industrial. Na visão extremamente otimista de Klaus Schwab (2016), tal processo não se trata de uma extensão das outras revoluções, mas sim de algo inédito e nunca vivido anteriormente pelas sociedades. De certa forma, até é possível pensar em algumas características peculiares do momento atual, como por exemplo, passando de um paradigma de mudanças atomizadas e estanques, a algo distribuído e sistêmico, não somente falando em rede de pessoas, mas também de tecnologias. Um exemplo dessa situação mediante a TA seria a obtenção de um produto simples, como um adaptador de escrita por exemplo, através da impressão 3D. Enquanto há anos atrás haveria uma dependência da loja física para sua comercialização, nos dias atuais o indivíduo poderia ter acesso a um arquivo digital de um modelo, compartilhado em uma plataforma de projetos imprimíveis na internet (como o Thingiverse, por exemplo), trocando informações com outros usuários e adequando seu projeto conforme suas necessidades, em um processo regido pelo fragmentado "eu-coletivo". Esse modelo poderia ser impresso em domicílio, no caso de se possuir uma impressora 3D desktop, ou ser enviado a um

11 "A Internet das Coisas (IoT) é um conceito no qual os dispositivos e objetos do nosso dia-a-dia são equipados com sensores capazes de comunicar entre si de forma inteligente. (...) Na sua essência, a loT significa apenas um ambiente que reúne informações de vários dispositivos (computadores, veículos, smartphones, semáforos, etc.) e de aplicações (qualquer coisa desde uma aplicação de media social como o Twitter a uma plataforma de comércio eletrônico, de um sistema de produção a um sistema de controlo de tráfego) (SANTOS, 2016, p. 8). 
local como um Fab Lab privado ${ }^{12}$. Porém, não é possível conceber essa situação hipotética sem tocar na questão de privilégios dos indivíduos.

Dado este cenário, é importante pensar a quem este modelo serve, de acordo com um recorte do público formado pelas pessoas com deficiência. Com este intuito, abrem-se aqui parênteses, situando a análise em território brasileiro. De acordo com dados do último Censo do IBGE (2010), todas as taxas relativas à escolarização da PcD estão abaixo das pessoas sem deficiência, como de escolarização básica ao ensino superior. Isso, por sua vez, leva a uma consequência posterior em termos de obtenção de renda, na medida em que é possível verificar que a média de ganhos das pessoas com deficiência também fica bem abaixo, sendo que 46,5\% delas vivem com um salário mínimo mensal (IBGE, 2010). Claro que nesse panorama também se inclui uma miríade de lacunas, como a falta de apoio à educação especial, o preconceito e a estigmatização da PcD na sociedade, o que torna a análise toda mais complexa e delicada. E assim, tendo em vista este acúmulo de fatores, não é possível que se espere que o acesso a outros pontos básicos, como serviços públicos e atividades de formação em geral, sejam de fácil acesso a esta fatia da população. Lembra-se aqui que a marginalização da $\operatorname{PcD}$ não é um caso isolado à cena nacional, mas sim um fenômeno histórico de categoria mundial (PACHECO; ALVES, 2007).

Posto isso, parte-se para uma reflexão de acordo com as possibilidades da Indústria 4.0 na área de atuação das TA's. O potencial imenso de uma indústria que abarca toda esta integração horizontal e vertical de suas redes, focando uma produção inovadora e com capacidade de saídas customizadas, soa como um ambiente altamente desejável para o fomento da Tecnologia Assistiva. Prosseguimos sentido a dois contextos possíveis.

Aqui encaramos dois dos cenários possíveis dentro dos quais a Indústria 4.0 pode contribuir ou não para a evolução das Tecnologias Assistivas. O primeiro deles, trata de recursos como os chamados wearables, ou tecnologias vestíveis, que são os objetos mais comentados quando o assunto é a Indústria 4.0. Esses produtos fazem uso de sistemas embarcados complexos, para se comunicarem e transmitirem grandes quantidades de dados ao seu usuário, praticamente sempre sob sua pele. Um exemplo mais conhecido deste tipo de produto é o Google Glass, que não

12 Vale recordar que existem Fab Lab's públicos no Brasil, a exemplo da rede Fab Lab Livre SP, implantada no ano de 2015 na cidade de São Paulo, atualmente com 12 unidades em funcionamento (FAB LAB LIVRE SP, $s / d$ ). Estes laboratórios são de uso gratuito e abertos à população. No entanto, frisa-se que estas iniciativas são pioneiras e ainda escassas no país. 
chegou a se transformar em realidade por conta de algumas especificidades, como seu alto custo (cerca de 1500 dólares americanos) e seus termos de privacidade, já que o objeto carrega uma câmera consigo (LOUREIRO et al., 2014). Gigantes tecnológicas como a Hewlett-Packard já estão em vias de adoção destes aparatos, com a finalidade de criar maior agilidade e produtividade em suas linhas de produção ${ }^{13}$. Óculos com uma proposta próxima aos recursos citados já estão à venda, voltados às pessoas com deficiência visual ${ }^{14}$, a quem auxiliam com a entrega de informações sonoras a respeito de obstáculos e trajetos a serem feitos. Outros mecanismos vestíveis assistivos também estão presentes no mercado nos dias atuais (Figura 03). Assim, tendo em mente as dificuldades de entrada da pessoa com deficiência no mercado de trabalho, seria uma alternativa interessante pensar nestes wearables para a inclusão, focando na conexão destas pessoas aos seus locais de trabalho, nesses ambientes imersos nas tramas da tecnologia.

Figura 03 - TalkTrac Wearable Communicator. Comunicador vestível para pessoas com autismo.
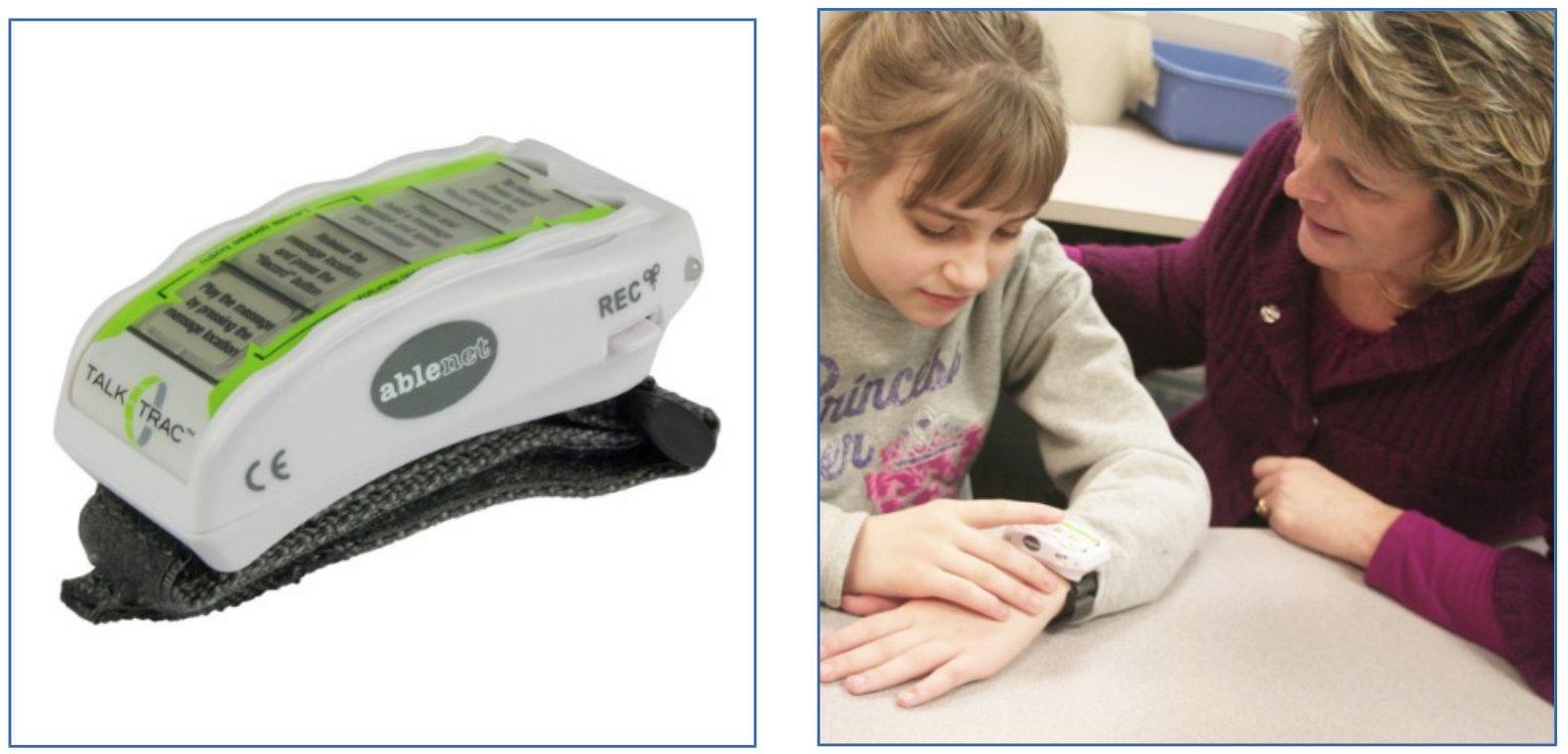

Fonte: ABLENET (s/d)

13 A entrevista com Jacques Spee and Keith Hudgell, ambos da Hewlett Packard Enterprise, está disponível no seguinte link: < https://www.youtube.com/watch?v=8912U4wRo1w > acesso 23 fev. 2018.

14 Um exemplo nesta área são os óculos NuEyes. O site da marca está disponível em: < https://nueyes.com/ > acesso 23 fev. 2018 
No entanto, como dito anteriormente, levanta-se aqui também a hipótese de um segundo cenário, menos otimista e promissor, dominado pelo desinteresse na produção de TA, devido a fatores já citados como a falta de uma demanda constante, os altos valores das tecnologias, contrastantes com a baixa renda da maior parte das populações a serem beneficiadas, e as necessidades de customização dos aparatos a serem desenvolvidos. Citam-se aqui somente os fatores pertinentes a esta análise, pois a lista de variáveis envolvidas neste âmbito vai muito além dos termos aqui expostos. Não muito dificilmente, visualiza-se que esta indústria maleável vem, potencialmente, ao encontro dessas demandas. A possibilidade do uso de altas tecnologias, onde ferramentas com maior capacidade autônoma (como a impressão 3D) possam ser utilizadas, apontaria para uma rapidez relativa, com capacidade de redução de custos com mão-de-obra e dos encargos daí derivados, sendo uma premissa possível levantada pela adoção deste viés produtivo. Claro que não se pode descartar o, igualmente potencial, aspecto destrutivo deste cenário, onde cada vez mais as indústrias passariam a ser zonas desertificadas, como ambientes esvaziados de empregados.

Salta-se novamente para o contexto nacional, o qual apresenta resultados pouco competitivos na área de inovação e produção customizada ${ }^{15}$, até o momento. Ou seja, uma indústria ainda imatura, convivendo com outros fatores hostis, como os índices de desemprego em crescimento, a precarização de leis trabalhistas e os cortes em investimentos nos setores de inovação, parece não ser um ambiente apropriado e amigável para suportar todos os contornos e impactos da Indústria 4.0. Tendo a consciência de não se deixar levar por devaneios tecnoutópicos, é possível falar em cenários potencialmente promissores em um futuro, mas com a devida cautela e noção de que os potenciais demolidores da tecnologia e de sua instrumentação em benefício de estruturas hegemônicas de poder econômico e político, além do constante perigo da alimentação de quadros hiperconsumistas, são ameaças reais a serem consideradas (ALVES, 2016). Sobretudo as tecnologias de fabricação digital apontam para uma fronteira interessante de produção a ser explorada na área de TA, soando já mais adequadas e compatíveis em contextos pouco estáveis, em termos econômicos e sociais.

15 Em entrevista à revista Exame, em julho de 2017, o professor Eduardo de Senzi Zancul, da Escola Politécnica da Universidade de São Paulo, faz análises da movimentação no Brasil ao redor da Indústria 4.0. Disponível em: <https://exame.abril.com.br/tecnologia/o-brasil-esta-pronto-para-a-industria-4-0/> acesso jan. 2018. 
Para finalizar, cita-se aqui um exemplo situado em um outro horizonte distinto do nacional: a Universidade de Flinders, na Austrália, já testa com sucesso seu Industry 4.0 Testlab - Assistive Technology Solutions, tendo apoiado o desenvolvimento de 185 startups em seu ambiente, trabalhando com processos co-participativos e de alta integração tecnológica na área de Tecnologia Assistiva (GALLAGHER, 2017).

\section{Considerações finais}

Este estudo buscou traçar alguns paralelos entre as potencialidades nos campos de desenvolvimento de produtos na área de Tecnologia Assistiva e das ferramentas da chamada Indústria 4.0, onde a impressão 3D encontra-se inserida. Visando ao fortalecimento da área de Tecnologia Assistiva, foram tecidas análises e relações hipotéticas sobre cenários de desenvolvimento no território nacional, os quais, infelizmente, carecem de uma maior atenção em áreas que precederiam a aplicação deste instrumental de tecnologia de ponta. No entanto, é reconhecida a potencialidade da Indústria 4.0 em trazer benefícios imediatos às Tecnologias Assistivas, em uma reflexão sempre atenta às expectativas falaciosas facilmente criadas e disseminadas em meio a cenários hiper-tecnológicos.

Trata-se, portanto, de um estudo preliminar baseado em reflexões e análises que vêm se intensificando em territórios, necessariamente, transdisciplinares. Durante os percursos da pesquisa, vem sendo constatada, inclusive, a necessidade de um foco mais atento dentro do escopo nacional nesta área, compreendendo a Tecnologia Assistiva como um campo vasto ainda a ser explorado, com capacidade de abranger diversas potencialidades e de se cruzar com diversos campos do conhecimento.

\section{Referências}

A B LENET. TalkTrac Wearable Communicator. S/d. Disponível e m: <https://www.ablenetinc.com/talktrac-wearable-communicator> Acesso dia: 26 fev. 2018.

ALMEIDA, W. J. de. Otimização estrutural de protótipos fabricados pela tecnologia FDM utilizando o método dos elementos finitos. Dissertacão (Mestrado em Engenharia Mecânica). Escola de Engenharia de São Carlos. Departamento de Engenharia Mecânica. Universidade de São Paulo: São Carlos, 2007, 100 p. 
AZEVEDO, M. T de. Transformação digital na indústria: Indústra 4.0 e a Rede de Água Inteligente no Brasil. Tese (Doutorado em Ciências). Escola Politécnica da Universidade de São Paulo. Departamento de Engenharia de Sistemas Eletrônicos. Universidade de São Paulo: São Paulo, 2017. $177 \mathrm{p}$.

BERSCH, R. Introdução à Tecnologia Assistiva. 2013. Disponível em: <http://www.assistiva.com.br/Introducao_Tecnologia_Assistiva.pdf>. Acesso em: 26 fev. 2018.

BUEHLER, E. et al. 2016. Investigating the implications of 3D printing in special education. ACM Trans. Access. Comput. v. 8, n. 3, mar. 2016, 28 p.

CRESWELL, J. W. Projeto de pesquisa: métodos qualitativo, quantitativo e misto. Porto Alegre: Artmed, 2010. 296 p.

ESTÚDIO $A B C$.O Brasil está pronto para a Indústria 4.0? Revista Exame. Disponível em: <https://exame.abril.com.br/tecnologia/o-brasil-esta-pronto-para-a-industria-4-0/> Acesso dia: 28 fev. 2018.

FABLAB LIVRE SP. Home. Disponível em: <http://fablablivresp.art.br/> Acesso em: 26 fev. 2018.

.TOGOTOY - brinquedo inclusivo. Disponível e m: <http://fablablivresp.art.br/projetos/19072016-1903/togotoy-brinquedo-inclusivo> Acesso dia: 26 fev. 2018.

GALLAGHER, S. Industry 4.0 testlabs in Australia preparing for the future: A report of the prime minister's industry 4.0 taskforce - industry 4.0 testlabs workstream. Swinburne Research: Hawthorn, 49 p., 2015.

GALVÃO FILHO, T. A.; DAMASCENO, L. L.. Programa InfoEsp: Premio Reina Sofia 2007 de Rehabilitación y de Integración. Boletín del Real Patronato sobre Discapacidad, Madri, n. 63, p. 14- 23, abr. 2008.

INSTITUTO BRASILEIRO DE GEOGRAFIA E ESTATêSTICA (IBGE). Censo demográfico 2010. Características gerais da população, religião e pessoas com deficiência. Disponível em: <http://biblioteca.ibge.gov.br/visualizacao/periodicos/94/cd_2010_religiao_deficiencia.pdf>. Acesso em: 27 fev. 2018.

ISHENGOMA, F. R.; MTAHO, A. B. 3D Printing: Developing Countries Perspectives. International Journal of Computer Applications, v. 104, n. 11, 2014, p. 30-34.

LEUNG, P. Introduction of 3 D Printing. Apresentação. Disponível em: <https://www.slideshare.net/noaizumi1/introduction-of-3d-printing> Acesso em: 28 fev. 2018. 
LOUREIRO, J. H.; BARBOSA, J. P.; CASTRO, J. P. Vestuário Tecnológico - "Wearable Computing": Desafios tecnológicos e sociais. Faculdade de Engenharia da Universidade do Porto. Projeto FEUP 2014/105. Porto, 2014, 14 p.

MATIAS, E.; RAO, B. 3d printing: on its historical evolution and the implications for business. In: Proceedings of PICMET '15: management of the technology age, PICMET 15', Portland, p. 551558, ago. 2015.

NETO, R. B. Século 21 tem crescimento de guerras civis, e internet está por trás disso. Folha de São Paulo. Disponível em: <http://www1.folha.uol.com.br/ilustrissima/2017/07/1905028-o-papelda-internet-nos-conflitos-armados-do-seculo-21.shtml>. Acesso em: 27 fev. 2018.

NUEYES. Home. Disponível em: <https://nueyes.com/> Acesso dia: 26 fev. 2018.

ORGANIZAÇÃO MUNDIAL DA SAÚDE (OMS). Relatório Mundial sobre a Deficiência. World Health Organization, The World Bank. São Paulo: SEDPcD, 2012.

PACHECO, K M. B.; ALVES, V. L. R. A história da deficiência, da marginalização à inclusão social: uma mudança de paradigma. Acta Fisiátrica, São Paulo, v. 14, n. 4, p. 242-248, dec. 2007.

ROBITAILLE, S. The illustrated guide to assistive technology and devices: tools and gadgets for living independently. New York: Demos Health. 2010. 207 p.

SANTOS, P. M. P. Internet das coisas: O desafio da privacidade. Dissertação (mestrado em Sistemas de Informação Organizacionais). Escola Superior de Ciências Empresariais. Instituto Politécnico de Setúbal: Setúbal, 2016, 96 p.

SEGALLA, J. I. da F.; DA SILVA, C. R.; PEDROSO, G. S. O idoso e a deficiência: um novo olhar à questão da inclusão social do idoso. In: Congresso Nacional do Conselho Nacional de Pesquisa e Pós-Graduação em Direito, 2008, Brasília. Anais... Brasília, 2008. 1017-1033 pp.

SODERBERG, J. A ilusória emancipação por meio da tecnologia. Le Monde Diplomatique. 2013. Publicação digital. Disponível em: <http://diplomatique.org.br/a-ilusoria-emancipacao-por-meioda-tecnologia/> Acesso em: 22 jan. 2018.

UNIFESP. Impressora 3D promete revolucionar mercado de próteses de mão. Disponível em: <http://www.unifesp.br/reitoria/dcik2/entreteses/item/2004-impressora-3d-prometerevolucionar-mercado-de-proteses-de-mao> Acesso em: 28 fev. 2018.

VENTOLA, C. L. Medical Applications for 3D Printing: Current and Projected Uses. P\&T, v. 39, n. 10, out. 2014. p. 704-711.

VERAS, R. Envelhecimento populacional contemporâneo: demandas, desafios e inovações. Rev. Saúde Pública, São Paulo, v. 43, n. 3, p. 548-554, jun. 2009. 
VIEIRA, G. OMS calcula que 35\% das mulheres já sofreram violência. Estadão. Disponível em: <http://www.estadao.com.br/noticias/geral,oms-calcula-que-35-das-mulheres-ja-sofreramviolencia,1045282>. Acesso em: 27 fev. 2018.

YOUTUBE. Mobile and Assistive Technology Makes Manufacturing Workers Smarter. The Business Value Exchange. Disponível em: <https://www.youtube.com/watch?v=89/2U4wRo1w> Acesso dia: 28 fev. 2018. 